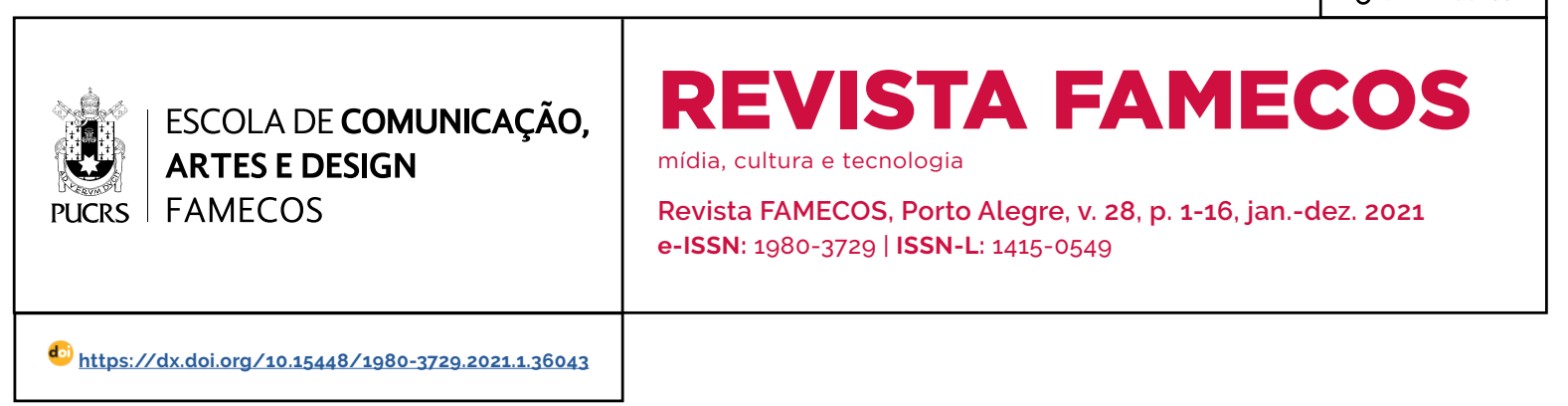

CINEMA

\title{
A censura a Prata Palomares (1971) e a construção da versão oficial sobre a luta armada
}

The censorship of Prata Palomares (1971) and the construction of the official version on armed struggle

La censura a Prata Palomares (1971) y la construcción de la versión oficial sobre la lucha armada

\section{Pedro Vinicius Asterito Lapera $^{1}$}

orcid.org/0000-0002-7547-1566 plapera@gmail.com

Recebido em: 17 out. 2019. Aprovado em: 19 maio 2021. Publicado em: 08 julho 2021.

\section{(c) (i)}

Artigo está licenciado sob forma de uma licença Creative Commons Atribuição 4.0 Internacional.
Resumo: Este artigo analisa a censura ao filme Prata Palomares (André Faria Jr.), produzido em 1971 e censurado no ano seguinte pela Divisão de Censura e Diversões Públicas (DCDP), tendo sido o filme totalmente interditado até 1976 - ano em que foi liberado para exibição em festivais - e permanecido fora do circuito comercial até 1983, quando foi distribuido pela Embrafilme. A questão que iremos trabalhar é: em que medida a censura ao filme inseriu-se em um conjunto de ações perpetradas pela ditadura civil-militar na construção de uma versão oficial sobre a luta armada? Assumimos como ponto de partida de nosso artigo o processo administrativo depositado no fundo da DCDP, mesmo que a obra filmica, o material de divulgação do filme e os artigos publicados na imprensa escrita sejam objeto de consideração em alguns aspectos. Como metodologia, empregamos a análise documental a partir da Diplomática.

Palavras-chave: Censura. Ditadura. Prata Palomares.

Abstract: This article analyzes the censorship of the film Prata Palomares (Andre Faria Jr.), produced in 1971 and censored the following year by Divisão de Censura de Diversões Públicas (DCDP), and the film was totally banned until 1976 - when it was released for exhibition in festivals - and was out of the commercial circuit until 1983, when EMBRAFILME distributed it. The question that we will be working on is: to what extent has the censorship of the film inserted itself in a set of actions perpetrated by the civil-military dictatorship in the construction of an official version on the armed struggle? We assume as a starting point of our article the administrative process deposited in the DCDP fund, even if the film, the film's publicity material and articles published in the written press are subject to consideration in some aspects. As a methodology, we use documentary analysis based on Diplomatics.

Keywords: Censorship. Dictatorship. Prata Palomares.

Resumen: Este artículo analiza la censura de loa película Prata Palomares (André Faria Jr.), producida em 1971 y censurada al año siguiente por la Divisão de Censura e Diversões Públicas (DCDP), que fue prohibida hasta 1976, año en que se estrenó em festivales - y permaneció fuera del circuito comercial hasta 1983, quando fue distribuida por EMBRAFILME. La pregunta que hacemos es: ¿ en qué medida la censura de la película se insertó en un conjunto de acciones perpetradas por la dictadura civil-militar en la construcción de una versión oficial de la lucha armada? Tomamos como punto de partida de nuestro artículo el proceso administrativo depositado en el fondo DCDP. Incluyemos en este trabajo la película, el material publicitario de la película y los artículos publicados en la prensa, que consideraremos en algunos aspectos. Como metodología, utilizamos el análisis documental basado en la Diplomática.

Palabras clave: Censura. Dictadura. Prata Palomares. 


\section{Introdução}

Tendo sido despertado de um sono conturbado, José caminhava em direção à padaria. Embora familiar, aquele percurso despertou-lhe estranheza e recolhimento. Janelas vazias, portas trancadas, poucas pessoas na rua que o cortavam apressadas e com medo latente.

Ao esperar o pão, olhou de relance a data no calendário pendurado ao lado da imagem de Nossa Senhora: 14 de dezembro de 1968. O clima sufocante era o prenúncio de um duro verão. Aumentaram o volume do rádio, que subitamente disparou:

se torna imperiosa a adoção de medidas que impeçam que sejam frustrados os ideais superiores da Revolução, preservando a ordem, a segurança, a tranqüilidade, o desenvolvimento econômico e cultural e a harmonia política e social do País comprometidos por processos subversivos e de guerra revolucionária (BRASIL, 1968).²

Após uma longa leitura, o locutor ponderou: "Infelizmente, precisamos dar um jeito nesses terroristas e nessa baderna que eles criaram". Terroristas? Baderna? Subversivos? E agora?

Mesmo que fictícia, a narrativa acima se insere em um horizonte de expectativas do cidadão comum no Brasil pós-Al-5. Mergulhada em um regime de exceção, a sociedade brasileira ficou à mercê de um aparato estatal voltado ao controle de informações e à perseguição de opositores políticos. Órgãos como DOI-CODI, ${ }^{3}$ DOPS, ${ }^{4}$ SNI, ${ }^{5}$ Cenimar 6 , $\mathrm{CIE}^{7}$ e Cisa ${ }^{8}$ atuaram em conjunto na repressão a grupos que resistiram aos desmandos da ditadura e que hoje são conhecidos como 'luta armada'.

Este artigo pretende se debruçar sobre um episódio pontual: a censura a Prata Palomares, dirigido por André Faria Jr. Tendo abordado a luta armada e suas consequências para as esquerdas e para o recrudescimento da ditadura, o filme foi submetido à apreciação do Serviço de Censura de Diversões Públicas (DCDP) em 1972 e totalmente interditado até 1976 para a exibição em festivais e por quase uma década até a exibição comercial.

A escolha por este filme ocorre em razão de o processo de censura referente a ele ser um caso- Limite na apreciação de obras cinematográficas brasileiras por parte do aparato censório da ditadura. Tal fato não se deu somente pela interdição total - isto é, em todos os circuitos de exibição - de Prata Palomares, ${ }^{9}$ mas principalmente pela rede mobilizada no interior do Estado brasileiro para que essa interdição fosse concretizada, conforme analisaremos ao longo deste artigo.

Ao se debruçar sobre a atividade de censura dos Estados modernos, Darnton (2016, p. 12-16) inferiu que haveria dois tipos possiveis de análise: uma com o foco no aspecto negativo da censura, isto é, em seu aspecto cerceador da liberdade de expressão e de criação artística, e outra com foco em seu aspecto positivo, ou seja, no mundo de representações ativamente produzidas pela atividade censória e sua projeção na esfera pública.

Sem desmerecermos os estudos que escolhem o primeiro caminho, reconhecemos que nossa análise terá como foco o 'mundo' produzido pela interdição

\footnotetext{
Trecho do texto original do Ato Institucional número 5 (Al-5), promulgado em 13/12/1968

Destacamento de Operações de Informação - Centro de Operações de Defesa Interna.

Departamento de Ordem Política e Social.

Serviço Nacional de Informação.

Centro de Informações da Marinha.

Centro de Informações do Exército.

Centro de Informações da Aeronáutica.

9 O que já o situaria como uma exceção, na medida em que poucos filmes foram interditados (considerando-se o volume total de filmes analisados pela DCDP). A interdição de uma obra representava um custo político por parte da censura, uma vez que o descontentamento por parte dos realizadores em torno dela poderia representar longas querelas administrativas que, inclusive, resvalavam às vezes para batalhas judiciais. Nessas disputas, havia o acionamento - por parte dos realizadores - de redes em defesa de seus filmes: críticos, jornalistas e até mesmo ocupantes que altos cargos burocráticos que pudessem intervir junto à DCDP para a liberação de suas obras. Embora haja alguns exemplos de filmes que foram interditados em todos os circuitos, ao longo do trabalho de campo feito nesta pesquisa desde 2010, raramente foram encontrados processos de filmes brasileiros e estrangeiros em que a interdição total foi adotada como procedimento, levando-se em conta o volume total de processos administrativos referentes a filmes que passaram pelo crivo da DCDP. É preciso não confundir a imposição de cortes a trechos de uma obra ou mesmo o veto à exibição no circuito comercial de cinema (de fato, mais comumente utilizados) com o procedimento da interdição total de uma obra. Não se trata de negar a violência simbólica imposta pela atuação do Estado a essas obras nem aos seus realizadores, mas de situar a interdição total de uma obra como um procedimento excepcional na rotina da DCDP. Inclusive, a notoriedade de alguns casos de obras totalmente interditadas revela justamente sua excepcionalidade, na medida em que o desgaste público propiciado pela divulgação desses casos na imprensa escrita era algo a ser evitado pelos dirigentes do órgão.
} 
a Prata Palomares. Mais precisamente, a questão que iremos trabalhar é: em que medida a censura ao filme inseriu-se em um conjunto de ações perpetradas pela ditadura civil-militar na construção de uma versão oficial sobre a luta armada?

Defendemos a hipótese de que essa censura foi englobada por uma politica de contrainformação adotada pelos dirigentes no periodo, com o intuito de agir em seu presente histórico através do cultivo de um sentimento generalizado de insegurança em relação aos opositores, qualificados pejorativamente sob a pecha do "terrorismo". Para tanto, consideramos a política de contrainformação uma estratégia de divulgação de informações que posteriormente se revelaram falsas ou deturpadas pelas midias impressas, sonoras e audiovisuais pari passu à censura de informações referentes às práticas de repressão da ditadura vigente (torturas, sequestros, execuções sumárias, prisões sem base legal, banimentos etc.), já analisada em seus desdobramentos por outros trabalhos (FICO, 2001; KUSHNIR, 2004. GASPAROTTO, 2012). Essas informações eram produzidas e veiculadas a partir de uma comunidade de informações (FICO, 2001) que atuava dentro da estrutura estatal em diferentes órgãos.

Além disso, consideramos a dimensão sistêmica e estruturante dessa política de contrainformação no período, intensificada a partir do acirramento das relações de poder na sociedade pós-Golpe de 1964 e exaltada com a promulgação do Ato Institucional n. ${ }^{\circ}$ 5, em 13/12/1968, embora seja necessário reconhecer que esse tipo de política já havia entrado em cena em momentos anteriores de nossa história republicana do Brasil. Desse modo, é possivel apresentar um panorama no qual uma memória oficial sobre a luta armada contra a ditadura foi construída por esse regime como um movimento radical, criminoso, violento, inconsequente e nefasto para a sociedade brasileira.
Assumimos como ponto de partida de nosso artigo o processo administrativo depositado no fundo da $D^{2} D^{10}$ e os pareceres, correspondências, instruções normativas, despachos e demais documentos nele contidos, mesmo que a obra filmica, o material de divulgação do filme, artigos publicados na imprensa escrita coletados nos arquivos da Embrafilme e documentos relativos ao filme em outros fundos custodiados pelo Arquivo Nacional ${ }^{11}$ sejam objeto de consideração em alguns aspectos. Neste panorama, não traçaremos uma linha cronológica rígida, uma vez que pretendemos posicionar o processo de censura ao filme em uma rede maior de fluxos documentais e de acontecimentos catalisados pela ditadura.

Ainda, é importante destacarmos que este artigo não se trata de uma revisão historiográfica dos movimentos de resistência à ditadura civil-militar no Brasili2. Bem mais modesto, nosso objetivo é o de tão somente situar o processo de censura a Prata Palomares em um esforço maior do regime em construir uma imagem pública desses movimentos através da comunicação massiva.

Precisamos sublinhar também que a escrita desse artigo está imersa em um momento de reforço de uma memória social bastante conservadora em relação à ditadura civil-militar e às suas práticas, que retira do contexto da repressão a trajetória dos movimentos de resistência a esse regime de exceção e produz uma sensação ilusória de conforto e progresso relacionada a supostas conquistas econômicas e sociais do regime vigente entre 1964 e 1985.

Como metodologia de pesquisa, empregamos a análise documental do processo guardado junto ao arquivo da DCDP a partir dos preceitos da Diplomática, tal como definidos por Bellotto (2014, p. 350). Segundo a autora, os documentos apresentam elementos estruturais capazes de revelar a sua posição no fluxo processual e nas atividades do órgão que os originou, tais como

\footnotetext{
10 Fundo DCDP, Seção Censura Prévia, Série Cinema, Subsérie Filmes, Caixa 297. Arquivo Nacional (Brasília).

11 Além do fundo da DCDP, encontramos documentos relativos a Prata Palomares nos seguintes fundos custodiados pela instituição: Superintendência para o Desenvolvimento da Região Centro-Oeste; Serviço Nacional de Informações (SNI), Divisão de Segurança e Informações do Ministério das Relações Exteriores; Divisão de Inteligência do Departamento da Polícia Federal; e Divisão de Segurança e Informações do Ministério da Justiça. Tal fato é um forte indicio de que a circulação do filme ultrapassou a dimensão da censura stricto sensu, caindo nas redes da chamada "comunidade de informações" (FICO, 2001, p. 12).

12 A respeito do tema, conferir: Gorender (1998) e Reis (1990).
} 
datas, carimbos, timbres, rubricas, assinaturas, além da própria forma física desses documentos (no caso, textual). Esses elementos são primordiais para situar a atividade censória e o modo através do qual a interdição total de Prata Palomares foi enquadrada pelo referido órgão.

\section{Nas artimanhas burocráticas: a censura a Prata Palomares no contexto da repressão à luta armada}

Contrariando expectativas quanto à pesquisa sobre filmes, nosso primeiro contato com Prata Palomares não se deu em uma sessão de cinema. Tivemos conhecimento sobre a obra durante a realização de um trabalho de campo no Arquivo Nacional, em Brasília, no qual nos debruçamos sobre os diferentes documentos deixados pela atividade censória. O processo referente ao filme chamou nossa atenção por conter documentos que, à primeira vista, diferiam do conteúdo da maioria dos processos ali guardados.

Depois da primeira incursão, procuramos o setor responsável pela guarda das matrizes dos filmes avaliados pela DCDP, no Arquivo Nacional - desta vez, no Rio de Janeiro - para tentar ver o filme em seu formato original (35 mm). Infelizmente, o setor ainda não havia digitalizado o filme, o que nos vetava o acesso a ele.

Essa situação foi contornada em virtude das novas tecnologias digitais, que permitiram uma maior disseminação de conteúdos de diversas matrizes na internet e achamos no site YouTube uma cópia completa do filme ${ }^{13}$, graças a qual podemos analisar a obra em seu conjunto e alguns trechos relevantes aos argumentos que defenderemos neste artigo.

A DCDP - órgão responsável pela censura aos filmes a serem exibidos no mercado brasileiro estava englobada pela estrutura do Ministério da Justiça e submetida diretamente à Polícia Federal. De acordo com o quadro de arranjo publicado ${ }^{14}$, pode-se extrair o fato de que havia censores e um setor voltados especificamente para os filmes, assim como a outras áreas (teatro, rádio, televisão, música), sendo essa atividade subordinada à Chefía da DCDP.

De acordo com as informações extraídas dos instrumentos de pesquisa do fundo DCDP ${ }^{15}$, podemos deduzir que o Setor de Cinema deixou uma massa documental de 869 caixas, com o total de 38567 processos administrativos relativos a filmes e 163 processos referentes à programação de cinemas, o que revela o volume de trabalho do setor que analisava filmes brasileiros e estrangeiros, que também precisavam do certificado de censura para ocuparem as salas de cinema brasileiras.

Apesar de a censura ter sido exercida no periodo democrático, sua estrutura foi paulatinamente sendo centralizada na sede da DCDP em Brasilia em detrimento dos escritórios regionais a partir do golpe de 1964 e esse movimento ampliou-se com a promulgação do Al-5 (SIMÕES, 1999; STEPHANOU, 2001; BERG, 2002).

Os processos administrativos que concernem a censura de filmes possuiam uma forma padrão: diretores ou produtores entravam com o requerimento de censura e enviavam a sinopse do filme com uma cópia do filme em $16 \mathrm{~mm}$ ou 35 $\mathrm{mm}$. Em seguida, técnicos da censura da DCDP manifestavam-se através de pareceres, que seriam a base da decisão da chefia da censura. Essa poderia variar desde a interdição completa até a liberação sem nenhum corte, passando pela liberação com cortes ${ }^{16}$ Ainda, poderia liberar para todas as faixas etárias ou interditar para menores de $10,12,14,16$ ou 18 anos.

No caso de o filme ser aprovado sem cortes, era emitido o certificado de censura por parte da DCDP, documento fundamental para que o filme fosse exibido. Se a resposta fosse negativa, recomendando interdição ou cortes na pelicula, os interessados poderiam recorrer ao chefe da Polícia Federal ou efetuar os cortes solicitados antes da emissão do certificado de 
censura. Permanecendo a resposta negativa, havia o recurso ao ministro da Justiça e, por fim, ao Conselho Superior de Censura, quando este foi criado em 1968.

Sobre Prata Palomares, uma breve descrição do filme. Dotado de uma forte carga alegórica em sua narrativa (XAVIER, 1993), Prata Palomares apresenta dois militantes/guerrilheiros (Carlos Gregório e Renato Borghi) que, em fuga, encontram Nossa Senhora das Dores (Ítala Nandi). O objetivo deles é chegar a um paraíso perdido chamado Maracangalha. Após um sonho, chegam a uma igreja. Nela, descobrem que um novo padre está para chegar à cidade. Em razão disso, um dos guerrilheiros assume a identidade do padre para terem tempo de planejar a fuga. Aproveitando-se do disfarce, tenta convencer a população do vilarejo a aderir aos ideais revolucionários. Entretanto, uma família de Brancos que domina a cidade e encena a repressão no filme atrapalha os planos dos guerrilheiros.

No processo administrativo referente à obra, após sua sinopse, há o ofício 921/71, que se trata de uma comunicação do Presidente do Instituto Nacional do Cinema (INC), Armando Troia (brigadeiro), ao chefe do Serviço de Censura de Diversões Públicas ${ }^{17}$. Ainda que possível, a comunicação entre membros superiores de diferentes órgãos a respeito de um filme específico não era comum.

Além disso, há um carimbo "reservado" na parte superior do documento, o que significa que ele não era passivel de consulta pública e seu conteúdo deveria permanecer em segredo por parte dos agentes públicos envolvidos, sob pena de sofrerem sanções administrativas e penais. Isto é, os interessados no processo decisório estavam completamente excluidos dessa comunicação, não podendo se defender do conteúdo do ofício, abertamente hostil à obra realizada por eles.

A introdução do ofício é marcada por um pedido de desculpas informal devido à aprovação de Prata Palomares como filme brasileiro por uma Comissão do INC, justificando-se que era um ato estritamente formal. Também, funciona como um desejo de que a concessão de Certificado de Filme Brasileiro a filmes operasse como um mecanismo de censura, tal como foi feito posteriormente (embora de forma velada) em alguns casos, sendo o filme Iracema, uma transa amazônica, dirigido por Jorge Bodanzky e Orlando Senna, um dos mais notórios exemplos ${ }^{18}$.

Em um trecho grifado com caneta vermelha e com uma seta apontada por alguém que teve acesso a esse oficio, Troia assim se refere ao filme:

Ainda recentemente, o filme intitulado "Prata Palomaris", produzido por André Luiz de Souza Faria, de $35 \mathrm{~mm}$, em Eastmancolor, foi exibido para a Comissão Especial do INC que, em uníssono, se pronunciou de forma contrária ao referido filme, tal a repugnância que essa produção inspirou a seus membros, não só porque a pelicula, emoldurada em um substrato nitidamente subversivo, agride as instituições religiosas, civis e governamentais, como também, porque se revela obra caótica, confusa, sem estrutura, amoral e inepta, elaborada que foicom a nitida intenção de subverter todos os valores humanos. E, no entanto, a referida Comissão, cuja finalidade, como frisei linhas atrás, é de apenas decidir se o filme é brasileiro ou não, se viu na dura contingência de conceder o Certificado de Filme Brasileiro a essa péssima realização do Cinema Nacional, embora se saiba que seu conteúdo será criteriosamente examinado por esse conceituado órgão, com o rigor que vem caracterizando sua excelente atuação (TROIA, 1971, p. 9. grifo nosso).19

O ofício assume um tom nitidamente acusatório endereçado à obra, ao considerá-la "emoldurada em um substrato nitidamente subversivo" (TROIA, 1971, p. 9), deixando à mostra que seu conteúdo e sua narrativa incomodaram alguns dirigentes do regime. Dentro dessa expectativa, o intuito do ofício é revelado: alertar o chefe da censura a respeito do conteúdo do filme e induzi-lo a interditar a obra. Como não era competência do INC promover a interdição da obra, o seu diretor não poderia tomar uma atitude nesse sentido, então resolveu agir através de um jogo de bastidores para que isso ocorresse na prática.

\footnotetext{
17 É preciso destacar que a própria criação do INC é um dos frutos da percepção da ditadura quanto à importância das instituições culturais para a legitimação do regime e para a propagação de seus ideais.

18 Sobre a censura a Iracema, uma transa amazônica (1974), conferir Lapera (2015)

19 É importante ressaltar que, para a paginação dos documentos, seguimos a ordem na qual eles estão dispostos no processo administrativo referente ao filme junto à DCDP.
} 
É necessário destacar também a associação feita no ofício de Troia entre subversão política e ataque às instituições e crenças religiosas. Retratadas como uma blasfêmia política e cultural, as "doutrinas estrangeiras perigosas" (TROIA, 1971, p. 9) - por exemplo, comunismo e socialismo, a que se referiam os militares nesses termos genéricos - eram veiculadas como grotescas e extremamente ofensivas ao povo brasileiro, em diferentes momentos históricos, sendo esse ponto retomado pelos dirigentes no Brasil pós-golpe de 1964. Em diversas fases do processo de censura a Prata Palomares, essa ligação seria retomada, como veremos adiante.

O ofício é encerrado com um convite ao chefe da censura para "estabelecer contatos para debatermos êstes e outros assuntos de interêsse comum, visando ao aperfeiçoamento cada vez maior de nossos serviços" (TROIA, 1971, p. 9-10), tendo em vista o objetivo de afinar o "entrosamento entre as repartições que dirigimos, tão intimos são os problemas de suas respectivas alçadas" (TROIA, 1971, p. 9).

Debruçando-se sobre o mesmo documento, Simões sublinha que:

O brigadeiro insiste numa aproximação entre o órgão de fomento (INC) e o órgão policial (a Censura), visando o aperfeiçoamento dos mecanismos de repressão sobre os filmes não simpáticos ao regime militar. Nada supreende naqueles tempos de grande capilaridade do sistema repressivo. Tendo consciência do conteúdo pornográfico da relação que propõe, o militar, travestido de dirigentes de autarquia, impõe-se a autocensura, daí o teor sempre reservado dos documentos (1999, p. 190).

Discordamos dessa interpretação, uma vez que a colaboração entre diferentes instâncias do Estado brasileiro durante o regime militar é fartamente documentada ${ }^{20}$. Esse fator isoladamente não era objeto de constrangimento e, portanto, não era visto como "pornográfico" pelos agentes da repressão. A isso, contrapomos que o carimbo "reservado" possuido pelo documento deve-se mais ao objetivo da carta em si, isto é, estimular a censura ao filme por parte de outro órgão sem que os interessados no processo tivessem acesso à comunicação e pudessem se defender dos argumentos lançados pelo diretor do INC.

Neste ponto, é importante destacar que esse oficio não é a fonte mais antiga sobre o filme encontrada por esta pesquisa. A informação 2914/74 do Serviço Nacional de Informações (SNI) trata de um dossiê sobre o diretor José Celso Martinez Corrêa com todas as informações acumuladas pelo órgão sobre ele. Nela, há a remissão ao Protocolo 5482 - PB 42, de 15/8/1970, que informa a realização do filme Prata Palomares na Itha de Santa Catarina e no qual

\begin{abstract}
solicita-se informar tudo o que puder sobre a empresa acima Iprodutora do filmel: idoneidade moral, grupo financeiro a que estejam vinculadas, antecedentes cinematográficos (se já produziram filmes e, neste caso, se de boa qualidade), se já tiveram problemas com a Censura Federal, etc. ${ }^{21}$ (BRASIL, 1974, p. 2).
\end{abstract}

Esse documento comprova que, antes mesmo de o filme ser submetido à avaliação da DCDP, os órgãos de informação já estavam cientes de que a obra estava em produção e provavelmente tinham informações sobre o conteúdo da obra.

O documento seguinte que consta no processo administrativo de censura a Prata Palomares é o ofício 159/72, de 18/4/1972, do general Nilo Caneppa Silva (diretor da Polícia Federal) ao secretário-geral do Ministério das Relações Exteriores. A partir desse ofício, a interdição ao filme ganharia um desfecho mais concreto.

Nele, Caneppa Silva relata ter visto em um jornal que o filme havia sido selecionado para o Festival de Cinema de Cannes (França) e havia sido exportado sem o aval das autoridades brasileiras competentes; um ato gravíssimo, em sua análise. Em seguida, relata o recebimento do ofício de Troia: "o SCDP recebeu informação do Instituto Nacional do Cinema de que o indicado filme contém vistas desprimorosas para o Brasil, circunstância que

\footnotetext{
20 Apenas no âmbito da DCDP, há a série Correspondência Oficial, englobando as subséries Ofícios de Comunicação e Solicitação e Informações Sigilosas que, juntas, totalizam seis caixas. Por sua vez, estas somam cerca de 750 documentos que, dentre outras atividades, reúnem a troca de informações entre a direção do órgão com outros nas diferentes esferas do Poder Executivo federal e estadual.

${ }^{21}$ BR_DFANBSB_V8_MIC_GNC_AAA_74079949_do001de0002 - Fundo Serviço Nacional de Informações, Arquivo Nacional, Brasília.
} 
bastaria, também, para lhe ser vetada a licença de exportação" (SILVA, 1972, p. 11, grifo nosso).

Sobre a circulação de informações durante a ditadura civil-militar, Gasparotto sumarizou a questão: "foi com este objetivo, de 'selecionar' o que deveria ser ou não mostrado e discutido pela população, que o governo aplicou a censura aos meios de comunicação social e às diversas formas de expressão artística" (2012, p. 120). A isso, acrescentamos a preocupação do regime com a autoimagem no exterior, no sentido de vetar a difusão de informações referentes aos grupos de oposição a ele e às próprias práticas empreendidas pelos agentes da repressão na violação aos Direitos Humanos.

A percepção do General Caneppa Silva em torno das "vistas desprimorosas para o Brasil" sinaliza a necessidade de se criar imagens que abordem de modo positivo o ideário nacional. Também é destacado o caráter preventivo da censura, isto é, evitar a produção de obras que desqualificassem o discurso oficial a respeito do regime e, na visão de seus membros, do próprio Brasil. Fico afirma que a ditadura vigente investiu em um imaginário secular em torno da grandeza da nação e de suas riquezas naturais na tentativa de criar uma comunicação com a população (FICO, 1997).

Na sequência inicial de Prata Palomares, uma floresta é mostrada devastada pelo fogo, atolada por uma lama tóxica e sobreposta a cenas como homens nus enforcados e pendurados por uma corda em troncos de árvores e um carro metralhado no qualjaz um corpo de um homem vestido de terno. Por ela, dois guerrilheiros percorrem perdidos em busca de um paraíso perdido chamado Maracangalha. Assim, nessa sequência, a imagem da floresta "poluída" tanto pelo fogo/lama quanto pelos referentes à repressão política choca-se com a visão idilica de natureza que permeia a propaganda política do governo ditatorial.

O ofício de Cánepa foi encerrado com a solicitação de que o Ministério das Relações Exteriores acionasse a embaixada brasileira na França para intervir junto ao Festival de Cannes, impedindo que o filme fosse exibido na Semana da Crítica, no que foi bem-sucedido: o filme foi retirado do festival após uma comunicação entre seus organizadores e a representação diplomática brasileira na França. ${ }^{22}$

Entretanto, ao nos debruçarmos sobre outra seção do fundo DCDP - desta vez, sobre a Administração Geral do órgão -, percebemos que o ofício do general Cánepa estava inserido em outros ofícios de comunicação com o Ministério das Relações Exteriores, que ajudam a revelar o debate ocorrido no interior da burocracia estatal sobre como agir diante do caso Prata Palomares. No ofício SG/DSI/DDC 123, de 4/5/1972, de caráter sigiloso, o secretário geral das Relações Exteriores Jorge de Carvalho e Silva ponderou a ânsia do general em censurar o filme, enfatizando que

\begin{abstract}
Ao que tudo indica, acrescenta o Embaixador, o filme "Prata Palomares", caso ali venha a ser exibido se diluirá num contexto mais amplo de películas do mesmo gênero, sendo ainda fato que as manifestações de contestação contra os Estados Unidos da América têm, pelo menos na França, maior acolhida pela imprensa do que as manifestações contra o Brasil.

Providências que fossem eventualmente adotadas pela Embaixada do Brasil para sustar a exibição da referida película poderiam portanto, a juizo daquela Missão, servir para sua maior promoção, através de artigos de alguns dos críticos, que são os próprios organizadores do certame paralelo e selecionadores dos filmes que serão ali projetados, havendo também o risco de não serem essas providências atendidas (SILVA, 1972, p. 2). ${ }^{23}$
\end{abstract}

O secretário geral encerra o ofício sugerindo uma manobra diplomática mais sutil, no sentido de informar as autoridades locais que o filme saiu ilegalmente no Brasil e, portanto, se encontrava em uma situação irregular no festival, uma vez que uma ação direta poderia causar ainda mais danos à imagem do Brasil.

Tal sugestão foi sumariamente ignorada pelo general Caneppa Silva que, no ofício 197/72, de 15/5/1972, informou ao Ministério das Relações Exteriores que: a) os produtores do filme haviam

22 Em comunicação apresentada ao XXII Encontro da Socine intitulada "Prata Palomares (1971): censura e tropicalismo no contexto pós1968", o pesquisador Adriano Del Duca (PPGCINE/UFF) relatou que houve a exibição do filme em uma sessão paralela ao Festival de Cannes em 1972, informação que conseguiu em uma entrevista realizada com o diretor André Faria Jr.

23 BR_DFANBSB_NS_AGR_COF_ISI_0057_doo01de0001. 
percebido a atuação do governo brasileiro para retirar o filme do festival e o submeteram às pressas para apreciação da DCDP; b) o filme foi proibido de ser exibido em território nacional e de ser exportado pela DCDP; c) a motivação para tal ato era o "substrato nitidamente subversivo" e ofensivo da obra. ${ }^{24}$

Um folheto de quatro páginas encontrado na pasta referente ao filme Prata Palomares nos arquivos da Embrafilme ${ }^{25} \mathrm{e}$ hoje custodiado pelo Cedoc/Funarte ${ }^{26}$ esclarece alguns pontos desse episódio. ${ }^{27}$ Recorda os protestos que ocorreram na edição do Festival de Cannes de 1972 por conta da manobra da diplomacia brasileira em interditar o filme, que reuniu diretores como Milos Forman, Sergio Leone e Roman Polanski e entidades como a Associação Francesa de Critica Cinematográfica, Sindicato de Cineastas Alemães e a Associação Pan-Africana de Cineastas.

É importante ressaltar que Prata Palomares não é um caso isolado no campo das artes. Enfocando a literatura do periodo da ditadura, Marcelino analisou o processo administrativo do livro Bar Don Juan, de Antônio Callado, publicado em 1971 e interditado no ano seguinte, assim como o filme aqui avaliado (MARCELINO, 2011, p. 65-68). Abordando os dilemas dos militantes de esquerda que aderiram à luta armada, a análise feita pela Delegacia Regional do DPF da Guanabara em torno do livro, segundo Marcelino, era "uma espécie de 'esfriamento', ou seja, uma demora proposital da resposta censória com vistas a diminuir seu impacto editorial" (MARCELINO, 2011, p. 67). ${ }^{28}$

No documento divulgado pelo autor que embasou a interdição ao livro, destacamos o seguinte trecho: "enquadra-se, destarte, entre os livros que podem pôr em perigo a segurança nacional [...] Por outro lado, em que pese a fama do autor, [...] em que pese a acolhida do público brasileiro à primeira edição, pode a obra incluir-se entre as que atentam contra a moral e os bons costumes" (grifo nosso). ${ }^{29}$ Desse modo, mais uma representação que veiculava de modo positivo a luta armada e seus militantes seria retirada do debate público, configurando um indício de que havia um esforço coordenado por parte de diferentes setores da burocracia em cercear representações positivas que ressaltassem a dimensão revolucionária dos movimentos de luta armada contra o regime.

No tocante ao processo administrativo de Prata Palomares junto à DCDP, o parecer assinado pela técnica de censura V. D. N. ${ }^{30}$ de 4 de maio de 1972 , reconhece que guerrilheiros em busca de um Paraíso são os personagens principais do filme. Destaca que um dos guerrilheiros se disfarça de padre para "celebra[r] missas e fazler] sermões criticando a religião católica, incitando luta de classes com protestos veementes às estruturas político-sociais, também exalta o amor livre e ressalta a necessidade de lutas armadas" (grifo nosso).

A técnica conclui pela interdição do filme, ressaltando que

é patente a mensagem de desagregação no campo da familia, da sociedade, etc. Em sintese, fere frontalmente os interesses nacionais, quer no terreno da moral, quer da politica, incidindo diretamente nas normas censórias do Dec. Lei 1077/70, art. 10. e 70.; Decreto 20.493, art. 41, letras "a", "b", "c", "d", "e", "f" e "g (V. D. N., 1972, p. 12).

Precisamos recordar que os incisos ' $d$ ' e ' $g$ ' do artigo 41, do decreto 20.493, afirma que será negada autorização à exibição de obra que "for capaz de provocar incitamento contra o regime vigente, a ordem pública, as autoridades constituidas e seus agentes" (BRASIL, 1946) e que "ferir, por qualquer forma, a dignidade ou o interêsse nacionais" (BRASIL, 1946).

\footnotetext{
24 Idem

25 Empresa Brasileira de Filmes, responsável pela distribuição da obra. O dossiê acessado contém o clipping do filme realizado pela própria Embrafilme (haja em vista o carimbo da instituição em cima do papel ao qual as notícias estão coladas). A prática do clipping era comum entre os anos 1960-90 como forma de documentar o impacto de uma obra ou artista na imprensa escrita.

26 Centro de Documentação da Fundação Nacional de Artes, localizado na região central do Rio de Janeiro.

27 Embora não seja datado, há menção à participação do filme no XII Festival de Cinema Brasileiro de Brasília, que aconteceu em 1979

28 O autor analisou outros romances que abordaram a luta armada e tiveram respostas negativas da censura, tais como Zero, de lgnacio Loyola Brandão e Em câmara lenta, de Renato Tapajós. Como esses livros são de um momento posterior à interdição de Prata Palomares, optamos por destacar a censura a Bar Don Juan, que coincidiu com o período em que o filme foi proibido.

29 Parecer do DPF/São Paulo, de 22/2/1972, citado por Marcelino. Idem, p. 68.

3o Optamos por abreviar o nome dos censores, por não considerarmos a informação em si relevante para a análise.
} 
Desse modo, o parecer explicita o incômodo da censura com a representação em torno da luta armada contra a ditadura e o vincula expressamente à sua interdição. Apontada no filme e reconhecida no parecer para a derrubada do regime, essa representação da luta armada estava relacionada à capacidade da obra de incitar os espectadores contra o regime vigente e, ainda, como um ferimento aos interesses nacionais supostamente encampados pelos agentes da repressão.

Na obra analisada, há algumas sequências em que há a alusão aos agentes da repressão. Destacamos a sequência em que a igreja é invadida por homens armados que escoltam uma familia chamada pela voz em off de Nossa Senhora das Dores de "familia de Brancos". Um homem de preto arromba a porta de entrada da igreja e é seguido por homens vestidos com uniformes pretos armados com metralhadoras. Em seguida, a família entoa uma música em alemão. Em seguida, a familia e os homens armados dirigem-se ao altar onde a cruz está situada enquanto Nossa Senhora das Dores - escondida - relata aos guerrilheiros: "eles mataram nosso padre e vieram trazer flores pro padre deles que vai chegar". ${ }^{11}$

Além de ser possivel ver nessa sequência um pastiche ao filme Noviça Rebelde (1965), ela aproxima a representação dos agentes da repressão à imagem da SS Nazista presente no clássico dirigido por Robert Wise. Os mesmos casacos pretos e a postura coletivamente orquestrada pelos agentes da repressão - traduzidos por um movimento unidirecional em relação aos reprimidos, a ostentação de fuzis, movimentos corporais claramente intimidatórios - podem ser verificados tanto na sequência final de A Noviça Rebelde quanto na entrada da igreja em Prata Palomares.

Somadas a isso, o filme veicula as práticas empreendidas pelo regime para calar seus opositores. Além das marcas de tortura nos corpos dos guerrilheiros anteriormente citadas, ainda há três sequências em que a tortura é explicitamente encenada.

Em uma delas, durante uma visita da família de Brancos à igreja, um pai-de-santo é trazido à força e passa a ser submetido a uma sessão de tortura que tem início na cadeira elétrica, continua no pau-de-arara e só é finalizada quando o carrasco corta a cabeça da vítima. A sessão de tortura é assistida por toda a família - incluindo uma criança, que ri praticamente durante toda a sequência -, que interage com o ritual, cuspindo e atirando restos de comida e bebida no torturado. A sequência é finalizada pelo sangue da vítima manchando as roupas brancas dessa familia, que olha sadicamente o corpo morto.

É possivel relacionar a apreciação da familia de Brancos em torno do ritual de tortura do pai-de-santo ao gozo pelo olhar por parte de alguns setores conservadores da classe média que apoiaram o golpe civil-militar de 1964. O voyeurismo sádico representado pela família de Brancos pode ser interpretado como um referente filmico da legitimação conferida por esses setores da classe média às práticas de perseguição, tortura e extermínio contra opositores politicos empreendidas pela ditadura, reafirmando a aliança entre civis e militares na manutenção de um regime de exceção.

Desse modo, podemos inferir que Prata Palomares apresenta aos espectadores uma representação bastante depreciativa quanto aos agentes da ordem e às suas práticas. Nesse sentido, a visão da técnica de censura sobre o potencial do filme de incitamento contra a ordem estabelecida encontra-se em consonância com as atitudes empreendidas pelos membros da comunidade de informações (FICO, 2001) em relação aos meios de comunicação social. Kushnir divulgou dois manuais de comportamento que foram distribuidos às imprensas do Rio de Janeiro e de São Paulo no dia da promulgação do Al-5. ${ }^{32}$ Dentre diversos itens, consta no manual distribuído no Rio de Janeiro: "2. Não deverão ser divulgadas notícias que possam: [...] veicular atividades subversivas, greves ou movimentos operários" (apud KUSHNIR, 2004, p. 108).

Já o manual distribuido em São Paulo é ainda mais explícito quanto à questão dos movimentos de luta armada:

31 Transcrição de trecho aos 32 minutos do filme Prata Palomares (1971) feita pelo autor

32 A autora menciona que a publicação original destes manuais foi feita pelo jornal Resistência na edição de $21 / 1 / 1969$ e foram cedidos a ela pelo jornalista Elio Gaspari (KUSHNIR, 2004, p. 108). 
10) Não publicar notícias sobre atos de terrorismo, explosão de bombas, assaltos a bancos, roubos de dinamite, roubo de armas, existência, formação ou preparação de guerrilhas em qualquer ponto do território nacional, ou sobre movimentos subversivos, mesmo quando se trate de fato consumado e provado (apud KUSHNIR, 2004, p. 108-109).

Fica evidente a preocupação dos autores do manual com a veiculação de informações referentes aos movimentos de luta armada. Além disso, situa a censura ao filme aqui analisado dentro de um panorama no qual há a interdição à veiculação de informações a esses movimentos, que pode ser vista como uma tentativa de os dirigentes do regime construírem uma versão pública referente à sua própria atuação, dentro de uma lógica que ressaltava o ufanismo e um falso consenso socialmente imposto.

Maia (2002, p. 469-511) abordou a lógica da comunidade de informações (FICO, 2001) especificamente voltada aos jornais alternativos, que via neles "uma das principais ferramentas oposicionistas 'no esforço subjetivo de conscientização e de modificação das condições subjetivas da população" (2002, p. 504), citando o encaminhamento do Ministério da Justiça 280/78.33 Uma das formas catalogadas pelo documento e ressaltadas pelo autor era incitação à luta contra o regime (2002, p. 506) que, dentre outras formas, poderia ser através da luta armada, cujas menções deveriam ser alvo de interdição. Assim, é possivel perceber um conjunto de intervenções em diferentes campos da cultura (cinema, literatura, imprensa corporativa e alternativa) referentes à veiculação de representações dos movimentos de resistência à ditadura.

A interdição à circulação de informações sobre a guerrilha mostrou-se como a primeira fase de um processo mais amplo de construção da imagem midiaticamente veiculada em relação aos opositores do regime, que seria sucedida de uma segunda fase, marcada pela depreciação das práticas e dos membros desses movimentos de luta armada, retratados como radicais e nocivos à ordem pública.
Esse apagamento operou dentro da lógica de recrudescimento do civismo, qualificado por Maia (2012) como a "exacerbação dlo] otimismo [...], [que] organizou o aparato discursivo e ideológico nacionalista-conservador em torno do projeto autoritário dos governos militares" (2012, p. 94). Em resumo, a autora sustenta que o regime solapava as divergências políticas entre os cidadãos em nome da nação, tida como um bem maior a ser defendido de inimigos internos (MAIA, 2012, p. 90-98).

Outro parecer no processo administrativo, de autoria da técnica de censura T. G. P., vai ao encontro do disposto no primeiro parecer, inclusive indicando os jovens guerrilheiros como protagonistas. Descrevendo o final do filme como "a população segue outro guerrilheiro e todos se anarquizam, numa total liberdade sexual, gerando um clima de quase-loucura e o guerrilheiro se autodestrói", T. G. P. sublinha que, em Prata Palomares, "as situações propostas vão de encontro aos princípios morais e religiosos da sociedade brasileira, emitindo, assim, uma falsa imagem do nosso país" (T. G. P., 1972, p. 13), sugerindo a interdição da obra com a mesma base legal que o primeiro parecer.

Neste ponto, é necessário destacar dois trechos de Prata Palomares. Após chegarem à igreja, os guerrilheiros tomam banho e, durante o ato, ficam evidentes as marcas de tortura em suas peles. A isso, um dos guerrilheiros (Carlos Gregório) contrapõe com um discurso veemente a favor da luta armada como subversão contra o regime vigente:

\begin{abstract}
em cada uma dessas feridas, eles tentaram me provar que o mundo não pode ser mudado, mas também hoje a violência emana de cada pedaço que sobrou do meu corpo. Ou o mundo muda pela violência do nosso corpo ou então não há mais esperanças. ${ }^{34}$
\end{abstract}

No segundo trecho, quase ao final do filme, o guerrilheiro disfarçado de padre (Renato Borghi) estimula os cidadãos a depredarem a igreja. Bancos são destruídos pela multidão em fúria, imagens sacras são violadas, o altar é derrubado. Nessa cena, o guerrilheiro grita histericamente: "Quebra! 
Quebra tudo!", ri e dança em volta dos escombros. Desse modo, a revolta popular contra a instituição religiosa é diretamente ligada à luta revolucionária empreendida pelos guerrilheiros, misturando as questões políticas stricto sensu e morais. ${ }^{35}$

Em ambos os pareceres da censura, a pulsão revolucionária aparece ao lado da decadência moral representada pela liberdade sexual dos personagens, o que corrobora a ideia de Kushnir (2004, p. 38) de que toda censura é política. Seguindo a argumentação da autora, podemos deduzir que a divisão entre a motivação de a censura ser por razões políticas stricto sensu ou morais pode mostrar-se equivocada e até mesmo contraproducente na análise de alguns casos concretos, na medida em que ambas as razões se encontram relacionadas ou, mais especificamente, as aparentemente 'morais' muitas vezes foram articuladas para mascarar as explicitamente "políticas".

Em consonância com os pareceres e com as ações anteriores empreendidas a partir dos oficios já mencionados, a portaria 024/72-SCDP, de 8 de maio de 1972, proibiu a exibição de Prata Palomares em todo o território nacional e reconheceu que conteúdo subversivo da obra foi a principal motivação para o ato. Tal fato gerou a reação do diretor e produtor André Faria Jr. que, através de seu procurador, requereu o acesso ao inteiro teor da decisão da DCDP e a devolução da única cópia do filme entregue à censura para poder remontar e apresentar o filme ao órgão ${ }^{36}$. Sublinhamos que, por conta de o processo administrativo possuir um documento classificado como "reservado", os interessados receberam somente uma carta enviada pela DCDP comunicando a interdição do filme, sem acesso aos argumentos das técnicas de censura que embasaram tal decisão.

Alguns anos depois, em carta de Rogério Nunes (diretor da DCDP) ao diretor e aos produtores do filme, de 18 de fevereiro de 1977, ${ }^{37}$ em resposta ao pedido para a liberação do filme em circuito comercial, este faz alusão à liberação concedida anteriormente para a exibição em festivais. Em outra carta, dessa vez a Wilson Queiroz (que sucedeu a Rogério Nunes na diretoria da DCDP), de 3 de abril de 1979, André Faria Jr. faz menção à exibição no Festival de Cannes (França) e de San Sebastián (Espanha) em 1976.

Enquanto o filme era interditado para qualquer faixa etária no Brasil, Kushnir (2004) e Gasparotto (2012) relataram diferentes aspectos da preocupação do regime ditatorial com a apresentação pública - mediada pelos meios de comunicação massiva - em torno dos militantes dos movimentos de luta armada. Kushnir destacou que a execução de militantes dos movimentos de luta armada era descrita por parte da imprensa como meros 'confrontos' e ainda que, por conta da censura imposta a ela ou da adesão de alguns jornalistas à repressão, a imprensa também ocultava mortes decorrentes de tortura e que eram forjadas pelos agentes da repressão para ganhar uma aparência de legalidade (KUSHNIR, 2004, p. 298-305).

Ainda, a autora (2004, p. 278-279) reuniu imagens que mostravam os "arrependidos", isto é, militantes usados pelo regime ditatorial como propaganda dirigida à população visando desestimular a participação na resistência a ela. ${ }^{38}$ Sobre eles, Kushnir sublinhou que "o intuito era afirmar, em cadeia nacional, que ser oposição ao governo era um exercício realizado por pessoas que, arrependidas, expunham quão sem sentido era o combate" (2004, p. 311).

Sobre os "arrependidos", Gasparotto (2012, p. 119-134) narrou que havia uma articulação entre diversos órgãos no intuito de conseguir o depoimento desses militantes e convencê-los a assumir essa postura publicamente:

Nos depoimentos e entrevistas concedidos posteriormente pelos protagonistas desses episódios, aparecem indicações de nomes de

\footnotetext{
35 Referência à cena aos 99-100 minutos do filme Prata Palomares (1971).

36 Em um requerimento encontrado no processo administrativo, o diretor acionou um advogado para fazer a solicitação a Rogério Nunes, o diretor do SCDP.

37 Consta a assinatura de itala Nandi (atriz e produtora do filme) confirmando o recebimento da carta.

38 Kushnir divulgou a foto do grupo de militantes da Vanguarda Popular Revolucionária (VPR) apresentados à imprensa da sede da Secretaria de Segurança Pública de São Paulo e a página do jornal Folha de S.Paulo com o título "Apresentado à imprensa o ex-terrorista Massafumi" como exemplos de ações midiaticamente empreendidas pela ditadura.
} 
delegados e funcionários ligados à Oban, ao Centro de Informação do Exército, ao Centro de Informações da Marinha, aos DOPS estaduais, à Polícia Federal e até mesmo ao Ministério da Justiça, que estariam veiculados à estratégia das retratações (GASPAROTTO, 2012, p. 123).

É interessante verificar que o período em que a burocracia estatal demonstrou maior preocupação com o conteúdo do filme - isto é, entre o segundo semestre de 1971 e 1972, quando o filme foi oficialmente proibido - coincide parcialmente com o periodo mencionado por Gasparotto (2012, p. 26) como o mesmo em que o maior número de depoimentos de "arrependidos" foi veiculado pelas mídias impressas e televisivas - a partir de maio de 1970 até o final de 1971 e, com menor frequência, até 1975

Isso significa que os realizadores de Prata Palomares tentavam exibi-lo justamente no momento de maior preocupação do regime ditatorial quanto à imagem desses movimentos de resistência pela luta armada. E a extensão do período de interdição total a ele até 1976 caminhou pari passu com a política oficial de se evitar o tema na cena pública brasileira e internacional.

Considerando ainda que os órgãos de informação tinham conhecimento da produção do filme desde - no mínimo - o início de agosto de 1970, inferimos que o ciclo do filme coincide em sua totalidade com o período de maior alarmismo por parte da comunidade de informações (FICO, 2001) quanto a qualquer representação positiva a respeito dos movimentos de luta armada que pudesse furar o bloqueio imposto por ela.

Assim, Kushnir (2004) e Gasparotto (2012) demonstraram que havia um esforço coordenado entre diversos órgãos do governo ditatorial na construção da imagem pública através dos diferentes meios de comunicação massiva sobre a luta armada e seus militantes. Isso ratifica nosso argumento de que, enquanto representações que validassem a atuação dos movimentos de luta armada e que mostrassem os militantes de formas positivas/heroicas eram cerceadas de circular pela cena pública, outras representações
- mais teratológicas, certamente - ganharam força no imaginário coletivo, graças à difusão alcançada junto aos meios de comunicação social. Em suma, o mundo representado pelos agentes da repressão passava pela construção de um falso consenso obtido através da violência e do silenciamento voltados contra seus opositores.

Após a liberação para festivais, a batalha travou-se em torno da autorização para a exibição no circuito comercial. Por conta dessa liberação, o filme foi o vencedor do Prêmio Margarida de Prata - concedido pela Confederação Nacional dos Bispos do Brasil (CNBB), entidade vinculada à Igreja Católica - em 1978. Tal fato foi usado pelo diretor para contra-argumentar que o filme ofendia o sentimento religioso dos católicos ${ }^{39}$, porém sem sucesso. O parecer 1601/78 - assinado por cinco técnicos de censura - manteve o veto ao filme, ressaltando que "a película explorada em circuito comercial deixaria no público em geral impressões negativas de violência e deboche total dos valores religiosos e morais" (D. S. F; R. E. M.; A. P.; Y. L. N. P.; M. A. R. R., 1978, p. 41), mesmo reconhecendo a relevância da concessão de um prêmio por parte de uma entidade católica ao filme. Novamente, o medo da exposição do conteúdo do filme seria usado como argumento para o interditar.

Ao analisar os movimentos de anistia, Resende (2015) debruçou-se sobre o monitoramento dirigido a eles pela comunidade de informações (FICO, 2001). Tendo como foco o fundo do SNI, custodiado pelo Arquivo Nacional, Resende (2015, p. 77-80) trouxe à sua análise documentos também de 1978 e de 1979, que demonstram o incômodo por parte dos membros dessa comunidade quanto às narrativas de militantes que aderiam à luta armada ganhando a cena pública. Ainda, causava constrangimento a esses membros a atuação dos parentes dos desaparecidos, que denunciavam os sequestros, as sessões de tortura e as mortes.

Reproduzimos um dos documentos avaliados por Resende, produzido pela Agência Central do SNI (RESENDE, 2015, p. 79), cujo foco era o I Congresso Nacional de Anistia: 
Após a sanção da Lei de Anistia, que não atendeu à principal reivindicação dos movimentos, que era a anistia total, estes passaram a exaltar subversivos por ocasião do seu retorno ao pais, ou quando eram postos em liberdade os que se encontravam presos. Atualmente, estão se manifestando publicamente para homenagear os terroristas mortos em confronto com os órgãos de segurança. Nessas ocasiões, os terroristas são apresentados como heróis, conforme ocorreu no último dia 18 de setembro, por ocasião do aniversário da morte de Carlos Lamarca (BRASIL, Serviço Nacional de Informações, 1979, grifo do original apud RESENDE, 2015, p. 80).40

Mesmo na fase de distensão do regime, os membros da comunidade de informações (FICO, 2001) demonstravam apreensão em relação às narrativas envolvendo a luta armada e seus militantes. A liberação ao filme só viria no ano seguinte à última interdição, quando o filme foi submetido a nova apreciação. No parecer 5016/79, de 11 de outubro de 1979, a técnica de censura J. F. C. faz alusão às cenas de tortura na descrição do filme e, em sua conclusão ${ }^{41}$ ressaltou que:

Muito embora referindo-se como alegoria tendendo ao hermetismo, o filme permite situar um momento histórico anterior, suficientemente explorado pelos meios de comunicação. Entretanto, o metaforismo das proposições, agravado pela monotonia cênica, dificultará a apreensão desse contexto por uma plateia menos preparada para absorvê-lo. Isto posto, acreditamos que a referida abordagem politica, atualmente enfraquecida em sua possivel força incitativa, e a presença de cenas de tortura, ajustam-se ao público adulto, levando-nos a sugerir a liberação integral para a faixa etária máxima (J. F. C., 1979, p. 44-45).

Por sua vez, no parecer 4929/79, de 17/10/1979, a técnica de censura M. G. S. P. adverte para outros aspectos no tocante à liberação da obra:

[...] verifica-se que as produções semelhantes em termos de estilo cinematográfico e temática, que atualmente se acham em exibição no circuito comercial, não alcançaram êxito junto à grande massa frequentadora de cinemas, o que nos leva a entender que espetáculos desse gênero são praticamente nulos em termos de comunicação social, de diversões públicas, não possuindo força para alterar comportamentos.
Considerando, ainda, o momento político vivido pela nação, de reimplantação do processo democrático, onde se propaga a liberdade de expressão e escolha, seria incoerente continuar negando a liberação do filme em pauta. Assim julgando, propomos que a sua aprovação seja procedida com a classificação etária máxima, tendo em vista o seu conteúdo, o impacto dramático de suas cenas, por vezes carregada de forte grau de violência, além do risco de interpretações errôneas do ponto de vista moral e religioso, se a película for exposta a uma plateia imatura (M. G. S. P., 1979, p. 47V).

Depois de um entrave burocrático de quase uma década, finalmente foi publicada a portaria 026/79-DCDP, de 6 de novembro de 1979, que revogou a interdição de Prata Palomares no território nacional e, com isso, o filme recebeu o certificado de censura para exibição no circuito comercial de cinemas, com vedação a menores de 18 anos.

Mesmo assim, ainda houve um intervalo entre a liberação do filme pela DCDP e seu lançamento, que só aconteceria no início de 1983 no Rio de Janeiro e em São Paulo e no ano seguinte em outras capitais como Belo Horizonte e Curitiba, de acordo com algumas notícias encontradas sobre o filme em periódicos depositados no Setor de Publicações Seriadas, da Biblioteca Nacional e, também, no Cedoc/Funarte, na pasta referente ao filme.42 Ocupando os cadernos de cultura de alguns dos jornais de maior circulação, as notícias destacaram o longo período de censura a que o filme tinha sido submetido e algumas relacionaram o fato diretamente à representação da luta armada no filme (inclusive no título dessas notícias).

Sobre essa lacuna temporal, Del Duca (2017. p. 203) a atribuiu ao desinteresse por parte de distribuidores em comercializar um filme com mais de 10 anos de realização e relatou que tal impasse foi resolvido com um contrato entre os produtores do filme e a Embrafilme. Ainda, situou-a perante mais um impasse burocrático junto à DCDP, dessa vez em relação ao trailer do filme, o que é confirmado pelo parecer 967/83. encontrado em nossa pesquisa no processo

40 Arquivo Nacional. ACE 4214/79. Fundo SNI.

41 Há outros pareceres no processo referente a Prata Palomares cuja análise vão no mesmo sentido do parecer exposto.

42 A título de exemplo, citamos: notas publicadas sobre o filme publicada nas edições de 12/12/1982 e de 07/05/1983 no jornal O Fluminense (Niterói, RJ); outra na Folha da Tarde (São Paulo, SP) em 9/3/1983; outras no jornal O Globo (Rio de Janeiro, RJ) de 6/5/1983 e de 8/5/1983; outra no O Estado de S. Paulo (São Paulo, SP) em 8/5/1983; outra no jornal O Dia em 9/5/1983; o artigo "Violência Prateada" no jornal O Estado do Paraná (Curitiba, PR); o artigo "Questionando o Brasil" no jornal O Estado de Minas (Belo Horizonte, MG) em 26/5/1984. 
administrativo do filme junto à DCDP.

Mesmo após seu lançamento, o filme não deixaria de escapar à vigilância dos órgãos de segurança. A informação no. 22/0561/G-2/83, distribuída pelo SNI a pelo menos três órgãos, ${ }^{43}$ elencou o filme como uma das obras que atacavam o governo nas diversas mídias, salientando que se tratava de um relatório elaborado semanalmente sobre vários meios de comunicação e artes (principais jornais de grande circulação, teatro, cinema, televisão e rádio). Essa informação era um documento produzido semanalmente a respeito desses meios e de matérias, artigos, reportagens etc. que fossem depreciativos ao governo e ao regime, havendo uma avaliação quantitativa desse material por temas abordados, tais como: política econômica, propaganda comunista, imagem dos Ministérios, divida externa e fusão das oposições.

Sendo um documento classificado como confidencial, ${ }^{44}$ assim descreveu o filme: "realizado em 1970, com a participação do GRUPO TEATRO OFICINA, envolve a questão da guerrilha, numa atmosfera impregnada de onirismo e imagens nítidas da cultura brasileira"45 (BRASIL, 1983, p. 9 , grifo nosso). Mais uma vez, a questão da luta armada é apontada como incômoda pelos agentes da comunidade de informações (FICO, 2001), que viram no filme uma das formas de 'propaganda adversa ao regime'.

\section{Considerações finais}

Uma avaliação do filme feita pela crítica de cinema no momento da exibição do filme no circuito comercial brasileiro apontou para o fato de que sua narrativa era "datada". Ainda, lamentava-se que, se a obra tivesse sido lançada no momento imediatamente posterior à sua produção, talvez tivesse outro impacto nos debates sobre a cultura politica no Brasil e sobre a ditadura.
Desse modo, a censura ao filme inseriu-se na tentativa de criar uma nova versão sobre a luta armada por parte do regime ditatorial, que mitigava seu potencial revolucionário e reduzia seus militantes a pessoas inconsequentes, voluntariosas e de má índole. Tal esforço remete à dialética entre a criação e a destruição caracteristica da modernidade, que perpassou a comunicação massiva, a tentativa de construção de um consenso e a moldagem das memórias coletivas de diferentes grupos sociais.

Através da análise da documentação referente ao filme Prata Palomares, foi possível verificar que a censura a ele fez parte da construção de uma versão pública aduladora da atuação dos militares, na qual a imagem pública dos movimentos de resistência à ditadura pela luta armada era ridicularizada e alvo da teratologia pelos agentes da repressão, enquanto seus membros eram alvos de encarceramentos arbitrários, torturas e mortes nos bastidores.

Os censores atestaram no filme uma contestação ao regime vigente em várias frentes: a) ataque ao repertório cultural legitimado pelo regime, incluindo neste ponto as imagens religiosas; b) depreciação da retórica otimista construida pela propaganda do regime; c) defesa da luta armada como forma de resistência à ditadura; e d) denúncia das práticas do regime em torno da tortura e da execução sumária de militantes.

Nesse sentido, o regime ditatorial foi parcialmente bem-sucedido em criar pânico moral em relação a esses movimentos de resistência pela luta armada que a combatiam física e simbolicamente, retardando a discussão sobre sua atuação o máximo que conseguiu, inclusive pelo adiamento da circulação de obras como o filme avaliado.

Finalmente, podemos afirmar que, embora a repressão a ideias e vozes dissonantes tivesse encontrado mais um capítulo na ditadura civil-militar

\footnotetext{
43 Detectamos a mesma informação em três fundos diferentes: Superintendência do Desenvolvimento da Região Centro-Oeste, Divisão de Segurança e Informações do Ministério das Relações Exteriores e Divisão de Segurança e Informações do Ministério da Justiça, todos custodiados pelo Arquivo Nacional (Brasilia). Isto é, esta informação encontrava-se inserida nas redes de comunicação dos órgãos de informação da ditadura.

44 Tal como atestam o carimbo de "confidencial" na parte inferior de todas as páginas e o aviso carimbado "TODA E QUALQUER PESSOA QUE TOME CONHECIMENTO DE ASSUNTO SIGILOSO FICA, AUTOMATICAMENTE, RESPONSÁVEL PELA MANUTENÇÃO DE SEU SIGILO" (art. 12 do decreto no. 79099/77 Regulamento para salvaguarda de assuntos sigilosos).

45 BR_DFANBSB_TS_ASI_PJU_0019_doo01de0001 - Fundo Superintendência do Desenvolvimento da Região Centro-Oeste, Arquivo Nacional (Brasília).
} 
entre 1964 e 1985, esta foi uma prática largamente legitimada ao longo da história republicana marcada pelo autoritarismo e pela tutela dos militares. Daí o perigo do desejo de censura que paira como uma sombra sobre a cena pública brasileira ressurgir quando os ventos totalitários voltam a soprar.

\section{Referências}

BERG, Cleuza de Oliveira. Os mecanismos do silêncio expressões artísticas e censura no regime militar (Brasil. 1964-1984). São Carlos: EdUFSCAR, 2002.

BELLOTTO, Heloisa Liberalli. Arquivo: estudos e reflexões. Belo Horizonte: UFMG, 2014.

BRASIL. Presidência da República. Casa Civil. Subchefia para Assuntos Juridicos. Ato Institucional número 5, de 13 de dezembro de 1968. Diário Oficial da União, Brasilia, 13 dez 1968. Disponivel em: http://www planalto.gov. br/ccivil_03/ait/ait-05-68.htm. Acesso em: 21 jun. 2019

BRASIL. Presidência da República. Decreto 20493, de 24 de janeiro de 1946. Diário Oficial da União, Brasília, 29, jan. 1946. Disponivel: https://www2.camara.leg.br// legin/fed/decret/1940-1949/decreto-20493-24-janeiro-1946-329043-publicacaooriginal-1-pe.html. Acesso em: 20 jun. 2019

BRASIL. Ministério do Interior. Informação número 22/0561/G-2/83. Dossiê Propaganda Adversa. Superintendência do Desenvolvimento da Região Centro-Oeste, 11 páginas. Diário Oficial da União, Brasília, 1983

BRASIL. Protocolo 5482 - PB 42, de 15/8/1970. In: Informação 2914, de 27 de agosto de 1974, do Serviço Nacional de Informações. Teatro Oficina. José Celso Martinez Corrêa. Arquivo Nacional, Fundo SNI. Entrada digital na base SIAN/Arquivo Nacional: BR_DFANBSB_ V8_MIC_GNC_AAA_74079949_doo01de0002.pdf. Acesso em: 27 mar. 2019

DARNTON, Robert. Censores em ação: como os estados influenciaram a literatura. São Paulo: Cia. das Letras, 2016.

DEL DUCA, Adriano. Alegoria da catástrofe: a história da censura ao filme Prata Palomares. O Mosaico, Curitiba, n. 14, p. 185-204, jan/jun 2017.

DIVISÃO DE CENSURA DE DIVERSÕES PÚBLICAS. Parecer de D. S. F; R. E. M.; A. P.; Y. L. N. P.; M. A. R. R. sobre o filme Prata Palomares, de 4 de maio de 1978 Arquivo Nacional, Fundo DCDP, Seção Censura Prévia, Série Cinema, Subsérie Filmes, caixa 297, processo referente ao filme Prata Palomares, p. 41.

DIVISÃO DE CENSURA DE DIVERSÕES PÚBLICAS. Parecer de J.F.C. sobre o filme Prata Palomares, de 11 de outubro de 1979. Arquivo Nacional, Fundo DCDP, Seção Censura Prévia, Série Cinema, Subsérie Filmes, caixa 297. processo referente ao filme Prata Palomares, p. 44-45
DIVISÃO DE CENSURA DE DIVERSÕES PÚBLICAS. Parecer de M.G.S.P. sobre o filme Prata Palomares, de 17 de outubro de 1979. Arquivo Nacional, Fundo DCDP, Seção Censura Prévia, Série Cinema, Subsérie Filmes, caixa 297, processo referente ao filme Prata Palomares, p. 47

DIVISÃO DE CENSURA DE DIVERSÕES PÚBLICAS. Parecer de J.C.M. sobre o trailer do filme Prata Palomares, de 22 de fevereiro de 1983. Arquivo Nacional, Fundo DCDP, Seção Censura Prévia, Série Cinema, Subsérie Filmes, caixa 297, processo referente ao filme Prata Palomares, p. 54.

DIVISÃO DE CENSURA DE DIVERSÕES PÚBLICAS Portaria 026/79, de 6 de novembro de 1979, de José Vieira Madeira, diretor da Divisão de Censura de Diversões Públicas. Revoga a portaria 024/72-SCDP. Arquivo Nacional, Fundo DCDP, Seção Censura Prévia, Série Cinema, Subsérie Filmes, caixa 297, processo referente ao filme Prata Palomares, p. 49.

FARIA JR., André. [Carta]. Destinatário: Wilson Queiroz. Rio de Janeiro, 3 de abril de 1979. Carta de André Faria Jr. a Wilson Nunes, diretor da Divisão de Censura de Diversões Públicas, de 3 de abril de 1979. Arquivo Nacional, Fundo DCDP, Seção Censura Prévia, Série Cinema, Subsérie Filmes, caixa 297, processo referente ao filme Prata Palomares, p. 43.

FARIA JR., André. [Carta]. Destinatário: Rogério Nunes Rio de Janeiro, 25 de março de 1978. Carta de André Faria Jr. a Rogério Nunes, diretor da Divisão de Censura de Diversões Públicas, de 25 de março de 1978. Arquivo Nacional, Fundo DCDP, Seção Censura Prévia, Série Cinema, Subsérie Filmes, caixa 297, processo referente ao filme Prata Palomares, p. 37.

FARIA JR., André. [Requerimento]. Destinatário: Rogério Nunes. Brasilia, 22 de maio de 1972. Carta de André Faria Jr. a Rogério Nunes, diretor do Serviço de Censura de Diversões Públicas, de 22 de maio de 1972 [Requere a devolução da cópia do filme entregue ao SCDP]. Arquivo Nacional, Fundo DCDP, Seção Censura Prévia, Série Cinema, Subsérie Filmes, caixa 297, processo referente ao filme Prata Palomares.

FICO, Carlos. Como eles agiam - os subterrâneos da ditadura militar: espionagem e polícia política. Rio de Janeiro, São Paulo: Record, 2001.

FICO, Carlos. Reinventando o otimismo: ditadura, propaganda e imaginário no Brasil. Rio de Janeiro: FGV, 1997.

GASPAROTTO, Alessandra. O terror renegado: a retratação pública de integrantes de organizações de resistência à ditadura civil-militar no Brasil (1970-1975). Rio de Janeiro: Arquivo Nacional, 2012.

GORENDER, Jacob. Combate nas trevas. São Paulo: Ática, 1998.

INSTITUTO NACIONAL DO CINEMA. Ofício 921/71, de 27 de setembro de 1971, escrito pelo brigadeiro Armando Troia IComunica ao chefe do Serviço de Censura de Diversões Públicas a avaliação feita sobre o filme Prata Palomares no âmbito do órgão] Arquivo Nacional, Fundo DCDP, Seção Censura Prévia, Série Cinema, Subsérie Filmes, caixa 297, processo referente ao filme Prata Palomares, p. 8-10. 
KUSHNIR, Beatriz. Cães de Guarda: jornalistas e censores, do Al-5 à Constituição de 1988. São Paulo: Boitempo, 2004

LAPERA, Pedro. Entre brechas, cortes e rasuras: relações étnico-raciais e censura cinematográfica durante a ditadura militar. Famecos, Porto Alegre, v. 22, n. 2 , p. 82-98, abr./maio/ jun. 2015. Disponivel em: http:// revistaseletronicas.pucrs.br/ojs/index.php/revistafamecos/article/view/19927. Acesso em: 21 jun. 2019.

MAIA, Maurício. Censura, um processo de ação e reação. In: CARNEIRO, M. L. T. Memórias silenciadas: história da censura no Brasil. São Paulo: EdUSP, Imprensa Oficial do Estado: Fapesp, 2002, p. 469-511

MAIA, Tatiana do Amaral. Os cardeais da cultura nacional: o Conselho Federal de Cultura na ditadura civil-militar (1967-1975). São Paulo: Itaú Cultural, 2012.

MARCELINO, Douglas Attila. Subversivos e pornográficos: censura de livros e diversões públicas nos anos 1970. Rio de Janeiro: Arquivo Nacional, 2011.

NUNES, Rogério. [Carta]. Destinatário: André Faria Jr. Brasília, 18 fev. 1977. Carta de Rogério Nunes, diretor da Divisão de Censura de Diversões Públicas, ao diretor André Faria Jr., de 18 de fevereiro de 1977.Arquivo Nacional, Fundo DCDP, Seção Censura Prévia, Série Cinema, Subsérie Filmes, caixa 297, processo referente ao filme Prata Palomares, p. 25.

PRATA Palomares. Direção e roteiro: André Faria Jr., Produção: André Faria Produções Cinematográficas. Com Ítala Nandi, Renato Borghi, Carlos Gregório e Otávio Augusto. Brasil, 1971, colorido, 110 min, son., color, $35 \mathrm{~mm}$.

REIS, Daniel Aarão. A revolução faltou ao encontro os comunistas no Brasil. São Paulo: Brasiliense, 1990.

RESENDE, Pâmela de Almeida. Os vigilantes da ordem: a cooperação DEOPS-SP e SNI e a suspeição aos movimentos pela anistia (1975-1983). Rio de Janeiro: Arquivo Nacional, 2015.

SECRETARIA-GERAL DO MINISTÉRIO DAS RELAÇÕES EXTERIORES. Ofício SG/DSI/DDC 123, de 4 de maio de 1972, de Jorge Carvalho e Silva. IComunica ao chefe da SCDP a avaliação sobre o caso da exibição de Prata Palomares no Festival de Cannes] Arquivo Nacional, Fundo DCDP, Seção Administração Geral, série Correspondência Oficial, subsérie Informações Sigilosas, caixa 6 , documento 57, p. 1-2

SERVIÇO DE CENSURA DE DIVERSÕES PÚBLICAS. Ofício 159/72 - SCDP, de 18 de abril de 1972, do General Nilo Caneppa Silva. IComunica ao secretário-geral de Relações Exteriores a intenção de retirar do festival de Cannes o filme Prata Palomares] Arquivo Nacional, Fundo DCDP, Seção Censura Prévia, Série Cinema, Subsérie Filmes, caixa 297, processo referente ao filme Prata Palomares, p. 11 e 17.

SERVIÇO DE CENSURA DE DIVERSÕES PÚBLICAS. Ofício 197/72, de 15 de maio de 1972, do general Nilo Caneppa Silva. IComunica a decisão final de retirar o filme Prata Palomares do Festival de Cannes] Arquivo Nacional, Fundo DCDP, Seção Administração Geral, série Correspondência Oficial, subsérie Informações Sigilosas, caixa 6, documento 57, p. 5-6.
SERVIÇO DE CENSURA DE DIVERSÕES PÚBLICAS. Parecer de V. D. N sobre o filme Prata Palomares, de 4 de maio de 1972. Arquivo Nacional, Fundo DCDP, Seção Censura Prévia, Série Cinema, Subsérie Filmes, caixa 297. processo referente ao filme Prata Palomares, p. 12.

SERVIÇO DE CENSURA DE DIVERSÕES PÚBLICAS. Parecer de T. G. P. sobre o filme Prata Palomares, de 4 de maio de 1972. Arquivo Nacional, Fundo DCDP, Seção Censura Prévia, Série Cinema, Subsérie Filmes, caixa 297. processo referente ao filme Prata Palomares, p. 13.

SERVIÇO DE CENSURA DE DIVERSÕES PÚBLICAS. Portaria 024/72, de 8 de maio de 1972, de Rogério Nunes, chefe do Serviço de Censura de Diversões Públicas. Proibe a exibição de Prata Palomares em todo o território nacional. Arquivo Nacional, Fundo DCDP, Seção Censura Prévia, Série Cinema, Subsérie Filmes, caixa 297. processo referente ao filme Prata Palomares, p. 14.

SIMÕES, Inimá. Roteiro da intolerância: a censura cinematográfica no Brasil. São Paulo: SENAC, 1999.

STEPHANOU, Alexandre Ayub. Censura no regime militar e militarização das artes. Porto Alegre: EDIPUCRS, 2001.

XAVIER, Ismail. Alegorias do subdesenvolvimento: Cinema Novo, Tropicalismo, Cinema Marginal. São Paulo: Brasiliense, 1993.

\section{Pedro Vinicius Asterito Lapera}

Doutor em Comunicação pelo Programa de Pós-Graduação em Comunicação da Universidade Federal Fluminense (PPGCOM-UFF), em Niterói, RJ, Brasil; pesquisador da Fundação Biblioteca Nacional (FBN), no Rio de Janeiro, RJ, Brasil; docente do Programa de Pós-Graduação em Cinema e Audiovisual da Universidade Federal Fluminense (PPGCINE-UFF), em Niterói, RJ, Brasil.

\section{Endereço para correspondência}

Pedro Vinicius Asterito Lapera

Universidade Federal Fluminense

Programa de Pós-Graduação em Cinema e Audiovisual

Rua Alexandre Moura, 8, Bloco A - sala 202

24210-200

Niterói, RJ, Brasil

Os textos deste artigo foram revisados pela Poá Comunicação e submetidos para validação do autor antes da publicação. 